\title{
Proposed Method for Dealing with Boil-off Gas on board LNG Carriers during Loaded Passage
}

\author{
Walid M Bahgat $^{\ddagger \ddagger}$ \\ ${ }^{\dagger}$ Department of Marine Engineering, Faculty of maritime studies, King AbdulAziz University, Jeddah, Saudi Arabia \\ ${ }^{\ddagger}$ Engineering Upgrading Studies Institute, Arab Academy for Science, Technology \&Maritime Transport, Alexandria, Egypt
}

Corresponding Author: W M Bahgat, Department of Marine Engineering, Faculty of Maritime Studies, King AbdulAziz University, Jeddah (21589), Saudi Arabia.

Accepted 20 May April 2015, Available online 02 June 2015, Vol.3 (May/June 2015 issue)

\begin{abstract}
In tankers carrying liquefied natural gas a portion of the cargo, generally between 0.1 and 0.25 percent per day evaporates as a result of imperfect insulation. This boil-off gas has normally been used to fire the ship's boilers. In view of rising price of natural gas, it will be more economical to re-liquefy boil-off gas and returns it to the LNG cargo tanks. It is therefore desirable to provide means for solving the boil-off gas problem. This paper provides an overview of current transporting methods of natural gas by using different ways like pipelines, liquefied natural gas, compressed natural gas and pressurized liquefied natural gas. Also, it describes the boil-off gas problem in LNG carriers and the different methods of solving this problem which include venting BOG or burning it in the gas combustion unit or by using BOG as fuel. Moreover, it states the different re-liquefaction processes in order to return BOG to LNG cargo tanks. Finally, the proposed method is to handle this boil-off gas in two PLNG containers; each container has a capacity of 3612 cubic meters for capacity of 266000 cubic meters LNG carrier in order to save BOG quantity.
\end{abstract}

Keywords: LNG, PLNG, CNG, re-liquefaction, BOG

\section{Introduction}

Natural gas should be changed to liquefied natural gas (LNG) and refrigerated to a temperature of $-162^{\circ} \mathrm{C}$ which convert it from gas to liquid in order to reduce its original volume by 600 times. While, liquefaction plant by compression which is called (CNG) compressed natural gas and in this process the volume of boil-off gas changes to liquid $1 / 300^{\text {th }}$ its original volume. After words, one proposal for reducing refrigeration costs is to produce liquefied natural gas at temperatures above $-112^{\circ} \mathrm{C}$ and at pressure 17 bar. This pressurized liquid natural gas is referred to as PLNG to distinguish it from LNG which is at or near atmospheric pressure. PLNG requires significantly less refrigeration since PLNG can be more than $50^{\circ} \mathrm{C}$ warmer than conventional LNG. So, in this case the PLNG will be shipped in safe condition instead of warming LNG, returned it back to its gaseous state and transferred to natural gas customers by pipelines.

Conditions for LNG and a CNG concept are also shown in the table (1) for comparison. For LNG, these conditions vary slightly based on gas composition. For PLNG and CNG, the pressure and temperature can be varied to optimize the storage conditions based on project variables. In general, the cost of the facilities decreases DOI: http://Dx.Doi.Org/10.14741/ljmcr/23213124/3.3.2015.20 and the shipping cost increases as you move from LNG to CNG in the table.

Table 1 : PLNG storage conditions compared to LNG and CNG.

\begin{tabular}{|c|c|c|c|}
\hline & LNG & PLNG & CNG \\
\hline Pressure (bar) & 1 & 17 & 200 \\
\hline Temperature (ํㅡ) & -160 & -110 & 20 \\
\hline Cargo Density $\left(\mathrm{kg} / \mathrm{m}^{3}\right)$ & 440 & 350 & 200 \\
\hline
\end{tabular}

For efficient treatment of BOG, there are two methods; one is to use BOG as fuel for different propulsion alternatives and the other method is to return it to the cargo tank by re-liquefaction of BOG [1].

\section{Alternatives of Natural Gas Transportation}

There are different alternatives to transport natural gas by means of pipelines, liquefied natural gas, compressed natural gas and pressurized liquefied natural gas which were discussed as follows.

508|Int. J. of Multidisciplinary and Current research, Vol.3 (May/June 2015) 


\subsection{Natural Gas Transportation by Pipelines}

The alternative to transport natural gas by means of pipelines is a conventional method in which the gas leaves the source and arrives at its destination [2].

The pipeline pressures ranges from 700-1100 psig depending on the material and the age of the pipe [3].

\subsection{Liquefied Natural Gas}

LNG is other alternative to transport natural gas; it is transported at $-160^{\circ} \mathrm{C}$ temperature and ambient pressure [4]. This method is the most economic option for transporting gas over long distances (above 4000km) when compared with pipeline projects [5]. LNG involves four different procedures; gas cleaning, liquefaction, shipping and regasification. Liquefaction is the most expensive procedure followed by shipping and regasification.

Liquefaction technology consist in condensing natural gas 600 times while reaching a temperature of $160^{\circ} \mathrm{C}$. There are several different engineering approaches to this process that differentiate the proprietary technologies; the cascade process, the mixed refrigerant process, and the expander cycle process are the most used worldwide. The key differences among these processes are their use of different refrigerants, exchangers and number of refrigeration systems.

The majority of modern LNG carriers vary in cargo capacity which ranges from 135,000 cubic meters to 266,000 cubic meters [6].

\subsection{Compressed Natural Gas}

The compressed natural gas (CNG) is to compress the natural gas at pressures 200 bar and temperature $20^{\circ} \mathrm{C}$. There are two technologies of transporting CNG, first is the discovery of new pressure containment vessel which is called coselle and is already applied in a coselle CNG carrier of dead weight 60,000 ton with 108 coselles. The second technology for transporting CNG called volume optimized transportation and storage (Votrans) which includes the compression of natural gas and cooled it to lower temperatures, these ships carry the refrigerated compressed gas in a box called CNG module and each module contains horizontal pipes [5].

\subsection{Pressurized Liquefied Natural Gas}

A new technology of gas transportation called Pressurized Liquefied Natural Gas (PLNG) has been developed by ExxonMobil [7] in order to reduce the costs of transferring natural gas. The PLNG technology includes a special designed PLNG containers fitted in the ship to store the liquefied natural gas under pressure of 17 bar and temperature $-115 \circ$ C. Also, the PLNG technology has an increase in the liquefaction temperature in order to decrease the required refrigeration horsepower.
Additionally, the advantage of PLNG technology is to save in facilities costs.

\section{Boil-off Gas Problem in LNG Carriers}

Most of LNG carriers have the boil-off gas problem which takes place during storage, loading or discharging and the ship's voyage. LNG is stored in a liquid state at a temperature below its boiling temperature point and at atmospheric pressure. As a result of imperfect insulation, the heat enters the cargo tank during storage and transportation. So, a portion of LNG cargo evaporates gas which is called Boil-Off Gas (BOG) [8].

The boil-off gas averages $0.12 \%$ per day; LNG ships use the boil-off gas as fuel for the propulsion systems. However, the high fuel consumption of steam turbine with low thermal efficiency, compared to the low consumption of diesel engines with high thermal efficiency, results of their replacement [9].

\section{Methods of Solving Boil-off Gas Problem}

The methods of solving the BOG problem are to vent the boil-off gas to atmosphere or burn it in the gas combustion unit or utilize it as fuel for propulsion system.

The first solution is to vent the BOG to atmosphere in order to adjust the pressure of LNG cargo tank or burning it is prohibited in certain areas because it produces toxic vapours [10].

\subsection{Boil-off Gas Utilization as Fuel}

The boil-off gas contains the methane gas which is lighter than air, when using it as a fuel and in case of leakage it will exit from ventilation hatch openings outside the engine room. So, it can be exploded when any flame approach to it [11].

There are many propulsion options applied in LNG carriers which can utilize the BOG as fuel like steam propulsion, dual fuel diesel electric (DFDE), gas turbine and two stroke slow speed diesel engine with gas injection. Firstly, the steam propulsion system can be burn the BOG or heavy fuel oil in the main boilers but the thermal efficiency of this propulsion is lower than gas turbine. Secondly, the dual fuel diesel electric propulsion option uses either BOG or liquid fuel like diesel oil or heavy fuel oil. So that, if the quantity of BOG is reduced the DFDE will use diesel oil directly and transfer the BOG to the gas combustion unit. Thirdly, in gas turbines propulsion, forced BOG is used as primary fuel while the diesel oil is used as a secondary fuel in case of the reduction of natural gas. Finally, the BOG can be used as fuel for slow speed two stroke diesel engines with gas injection by means of high pressure gas compressor of piston type in order to inject the gas fuel into the compressed scavenging air $[12,20]$. 


\subsection{Boil-off Gas Re-Liquefaction Technologies}

There are many methods for natural gas re-liquefaction, but the most common methods of re-liquefaction which are used on board LNG carriers are as follows.

Firstly, the Tractebel Gas Engineering (TGE) process [13] for the re-liquefaction of boil-off gas (BOG) depends on Brayton Cycle. When the pressure increased in LNG cargo tank, the BOG escaped from the tank and compressed to pressure ranges from 3 to 6 bar. After that, the BOG is liquefied in the BOG liquefier entered to the tank pressure through a valve and distributed to every tank on board LNG carrier. Also, the liquefaction process is done by cooling the BOG with nitrogen gas in the plate fin type heat exchanger. Moreover, a three stage turbo compressor is used to compress nitrogen gas to high pressure which is cooled between each stage in a shell \& tube type heat exchanger to ambient temperature using seawater as cooling medium. After that, the BOG liquefier is supplied by the cold high pressure nitrogen gas in order to reduce the temperature of BOG to $-110{ }^{\circ} \mathrm{C}$. Then, the compander is provided by nitrogen to decrease it's temperature to $-180^{\circ} \mathrm{C}$.

Secondly, the technology for re-liquefying natural gas is called Hamworthy KSE [14] which depends on the Moss Re-liquefaction. This re-liquefaction process of boil-off gas depends on closed nitrogen cycle which releases the heat from it. The BOG compressor is used to compress the BOG and transfer it to the cold box. Then, the BOG is reliquefied by cooling it in the cold box by applying Brayton cycle in which the cooling medium is nitrogen. After that, the low duty compressor is used for cargo cycle in which the LNG tank is evacuated from BOG at pressure approximately around 1.06 to 1.15 bar. Also, the BOG is cooled in the cold box to $-163^{\circ} \mathrm{C}$ and at pressure 4.5 bar. Finally, LNG returns back to the cargo tanks through separator in order to remove the gas bubbles.

\section{Results and Discussions}

After reviewing, the IMO (International Maritime Organization) requirements which includes that each LNG cargo tank must be filled to $98 \%$ of its total volume in order to prevent entering of any liquid into ventilation pipeline. These requirements are taking into account when calculating the quantity of BOG which evaporates during the ship's voyage $[8,15]$.

The reasons of evaporating BOG during the voyage are as follows: [16, 17, and 18].

1. The entering of heat to LNG cargo tanks due to temperature difference.

2. Due to the free surface effect of LNG cargo when tanks are partially filled.

When the heat enters to the LNG cargo tank, a portion of natural gas is evaporated as a result of temperature difference between atmospheric temperature and cargo tank temperature.

In case of wave motion, the free surface effect of LNG cargo takes place when tanks are partially filled causing friction along tank sides which produce heat that's lead BOG [19].

In order to utilize the boil-off gas, calculation of BOG quantity must be carried out to the LNG vessels in order to know the loss of LNG during laden (loaded) voyage.

The volume of BOG can be calculated by the expression:

$V=B O R \times C \times M L$

where;

$V$ - Volume of boil-off gas in $\mathrm{m}^{3}$

$B O R$ - Boil-off gas rate in (\% / day)

$C$ - Cargo capacity in $\mathrm{m}^{3}$

$M L$ - Maximum loading in (\%)

Also, the mass of methane in boil-off gas is determined by the following equation:

$M=V \times \rho_{a v}$

where;

$M$ - Mass of boil-off gas in ton

$V$-Volume of boil-off gas in $\mathrm{m}^{3}$

$\rho_{a v}$ - Average density in ton $/ \mathrm{m}^{3}$

By multiplying the mass of boil-off gas in tons with the LNG price in US dollars, the cost of BOG losses can be determined.

Firstly, according to statistics which is carried out for 267 LNG carriers with different capacities ranges from $135000 \mathrm{~m}^{3}$ to $266000 \mathrm{~m}^{3}$ and by applying the above equations it can be calculate the volume of BOG in cubic meter per day $\left(\mathrm{m}^{3} /\right.$ day). Secondly, by knowing the rate of BOG which is $0.12 \%$ and by substituting with different cargo capacities for LNG carriers and taking into account the maximum loading percentage which is $98 \%$. After that, by using excel program the amount of BOG volume per day and the mass of methane in ton per day can be determined for each capacity of LNG carriers. Additionally, by knowing the LNG price which is $11 \$ / M M B T U$ and it can be converted to $564 \$$ /ton of LNG. Therefore, by multiplying the mass of methane by $564 \$$ the cost of the lost LNG cargo can be obtained from the following equation:

Loss in LNG Cargo $=$ BOG Mass $*$ LNG Price

where,

BOG Mass - (ton/day)

LNG Price - (USD)

Moreover, some graphs were drawn to indicate shows the relations between BOG capacity per day and LNG 
carrier capacity, the relation between mass of methane per day and LNG carrier capacity and the relation between BOG price per day and LNG carrier capacity for the first category of different capacities of LNG carriers which valid in the range from $135,000 \mathrm{~m}^{3}$ to $165,680 \mathrm{~m}^{3}$. By knowing the LNG carrier capacities for the first category, the BOG capacity per day, the BOG mass per day and the BOG price per day can be determined directly from the following equations (4), (5), and (6):

BOG capacity/day $=0.0012$ (LNG carrier capacity)

BOG mass $/$ day $=0.0005$ (LNG carrier capacity)

BOG price/day $=0.2918$ (LNG carrier capacity)

In the first category which ranges from 135000 cubic meters to less than 170000 cubic meters, the volume of BOG per day for 135000 cubic meters LNG carrier is $158.76 \mathrm{~m}^{3} /$ day while the volume of BOG per day for LNG carrier of capacity $165680 \mathrm{~m}^{3}$ is $194.83 \mathrm{~m}^{3} /$ day. So that, by applying the above equations the BOG mass per day can be obtained which is 74.61 ton/day for the capacity 135000 cubic meters and 91.57 ton/day for 165680 cubic meters. Finally, the BOG price per day which is lost from LNG cargo is 42084USD per day for the capacity 135000 cubic meters and 51648USD per day for 165680 cubic meters LNG carrier.

Additionally, the relations between BOG capacity per day and LNG carrier capacity, the relation between mass of methane per day and LNG carrier capacity and the relation between BOG price per day and LNG carrier capacity for the second category of different capacities of LNG carriers has been determined for the range from $170000 \mathrm{~m}^{3}$ to $266000 \mathrm{~m}^{3}$.

Finally, from the above graphs and by knowing the LNG carrier capacities for the second category, the BOG capacity per day, the mass of methane per day and the BOG price per day can be obtained by the following equations (8), (9) and (10):

BOG capacity/day $=0.0012$ (LNG carrier capacity)

BOG mass/day $=0.0005$ (LNG carrier capacity)

BOG price/day $=0.2918$ (LNG carrier capacity)

In the second category which ranges from 170000 cubic meters to 266000 cubic meters, the volume of BOG per day for 170000 cubic meters LNG carrier is 199.92 $\mathrm{m}^{3} /$ day while the volume of BOG per day for LNG carrier of capacity $266000 \mathrm{~m}^{3}$ is $312.81 \mathrm{~m}^{3} /$ day. So that, by applying the above equations the BOG mass per day can be obtained which is 93.96 ton/day for the capacity 170000 cubic meters and 147.02 ton/day for 266000 cubic meters. Finally, the BOG price per day which is lost from LNG cargo is 52994.79 USD per day for the capacity 170000 cubic meters and 82921.26 USD per day for 266000 cubic meters LNG carrier.

\section{Proposed Method for Dealing with Boil-off Gas}

After surveying on different methods of solving the BOG problem and according to the above statistics for 267 LNG carriers of different capacities ranged from 135000 cubic meters to 266000 cubic meters. It is noticed that the capacity of LNG carrier 135000 cubic meters, the loss in LNG cargo due to evaporation is 158.7 cubic meters per day. So that, if the voyage takes twenty days therefore the total volume of BOG during the voyage is equal to 3175 cubic meters. Additionally, for the capacity of 266000 cubic meters the volume of BOG per day is 312.8 then during the voyage, the total volume of $B O G$ is equal to 6256 cubic meters. So, economically, this means the total loss in LNG cargo during the voyage is 787,908 USD for the capacity of 135000 cubic meters and equal to $1,552,489$ USD for 266000 cubic meters LNG carrier.

So that, it had to be search for another method to solve this problem with minimum cost, this will be determined by the following proposed method.

According to, the technology of transporting natural gas which is called pressurized liquefied natural gas (PLNG). This new method which reduce the cost of delivering natural gas under pressure 17 bar and at temperature $-115{ }^{\circ} \mathrm{C}$ in the PLNG containment system which consists of 59 large vertically supported pressure vessels located within a compartment called cold box that is approximately $220 \mathrm{~m}$ long $\times 33 \mathrm{~m}$ wide $\times 49 \mathrm{~m}$ high The interior of the cold box is insulated to protect the ship steel from the cryogenic PLNG temperatures. The dimensions of the container and the materials used in the various parts which have $10 \mathrm{~m}$ diameter and $46 \mathrm{~m}$ height; this means that the capacity of container is equal to 3612.8 cubic meters.

The proposed method is to use this development in the LNG carrier in order to reduce the refrigeration cost which is applied in Qatar Gas LNG carriers.

The concept of the proposed method is to use one container in a cold box with dimensions $3.72 \mathrm{~m}$ length $x$ $0.55 \mathrm{~m}$ wide $\times 0.83 \mathrm{~m}$ height. This container and its cold box can be applied for 135000 cubic meters LNG carrier because the total volume of BOG during the voyage is equal to 3175 cubic meters while the pressure vessel capacity is equal to 3612 cubic meters which is adequate capacity to fill the container.

Moreover, for the capacity of 266000 cubic meters, the total volume of BOG during the voyage is equal to 6256 cubic meters. So that, in this case two containers can be used in a cold box with dimensions $7.45 \mathrm{~m}$ length $\times$ $1.11 \mathrm{~m}$ wide $\times 1.66 \mathrm{~m}$ height each one has a capacity 3612 cubic meters. Therefore, by applying this method it can reduce the cost of re-gasification process which is applied for LNG because PLNG container can be discharged directly to a regasification unit and transferred to the market without need for storing it in tanks. Also, the LNG carrier can be discharge these two containers from the ship in no time. 


\section{Conclusion}

This paper provides an overview of the different methods of transporting natural gas which includes pipelines, liquefied natural gas, compressed natural gas and pressurized liquefied natural gas. Moreover, it discusses the boil-off gas problem in LNG carriers and the different methods of solving BOG problem. Firstly, by venting BOG or burning it in the gas combustion unit. Secondly, by using BOG as fuel to be used for the propulsion system or the dual fuel boilers in steam turbine plant which save the fuel cost partially, but the remaining quantity of cargo is lost. In addition to the application of different reliquefaction technologies of boil-off gas which had been implemented on board Qatar Gas LNG carriers. Finally, statistics had been carried out for existing 267 LNG carriers with different capacities ranges from 135000 cubic meters to 266000 cubic meters and according to this statistics, calculation of BOG quantity is carried out in order to know the volume, mass and price of BOG per day. So that, from this calculation it has been determined the total loss in LNG cargo during twenty days voyage and its cost.

PLNG technology aims to lower the cost of moving gas from the field to the market. So that, liquefied gas can be transported under moderate pressures and warmer temperatures than conventional LNG which reduce the facilities required to treat and liquefy the natural gas.

According to PLNG concept, the research paper discusses the application of the proposed method which uses one PLNG container of capacity 3612 cubic meters in a cold box for LNG carrier of capacity 135000 cubic meters. This result is obtained after calculating the BOG capacity during the voyage which is equal to 3175 cubic meters.

Additionally, by calculating the BOG capacity during the voyage which is equal to 6256 cubic meters, in this case two PLNG containers can be used of capacity 3612 cubic meters each. So, this proposed method can be applied for 266000 cubic meters LNG carrier.

\section{Reference}

[1]. Oka, M. ; Hiraoka, K. ; Tsumura, K., Development of Next Generation LNGC Propulsion Plant and HYBRID System, Mitsubishi heavy industries, LTD., Mitsubishi Juko GIHO; 41, 6; 322-325, 2004.

[2]. Cranmore RG, Stanton E. Transport. In: Dawe RA, editor. Modern petroleum technology, upstream volume. Chichester: Institute of Petroleum, John Wiley and Sons Ltd; 2000. p. 383-408 Chapter 10.

[3]. BP statistical review of world energy, BP, London, UK; 2002. Available from: http: //www. bp.com/centres/ energy 2002 . See also http://www. bpgaseconomy. com for more detailed discussions and information.

[4]. Wang X., Marongiu M. (2008). The Potential of compressed Natural Gas transport in Asia. IPTC 12078. This paper was selected for presentation at the international petroleum technology conference held in Kuala Lumpur, Malaysia, December.

[5]. Economides M., Sun K., Subero G. (2006). Compressed Natural Gas (CNG): An Alternative to Liquefied Natural Gas (LNG) Journal SPE Production \& Operations Volume 21, Number 2. SPE 92047. Society of Petroleum Engineers. pp. 318-324.

[6]. The international group of liquefied natural gas importers, "LNG ships", 2011. http://www.giignl.org (accessed February 2011).

[7]. Papka S., Gentry M., Leger A., Bowen R. and Nelson E., Pressurized LNG: A New Technology for Gas Commercialization, proceeding of the fifteenth (2005) international offshore and polar engineering conference Seoul, Korea, June 19-24, 2005.

[8]. Dobrota D., Lalić B., Komar I., Problem of Boil - off in LNG Supply Chain, University of Split, Faculty of Maritime Studies, Zrinsko-Frankopanska, Split, Croatia, 2013.

[9]. Tarakad, Ram R., LNG Receiving and Regasification Terminals, An Overview of Design, Operation and Project Development Considerations, Zeus Development Corporation, Houston, Texas 2003.

[10]. International Chamber of Shipping, Tanr Safety Guide (Liquefied Gas), International Chamber of Shipping, London 1995.

[11]. Cusdin, D. R., The development of Liquefied Natural Gas Carriers - a marine engineering success, The Institute of Marine Engineers, London 1998.

[12]. R P Sinha and Wan Mohd Norsani Wan Nik, "Investigation of propulsion system for large LNG ships", 1st International Conference on Mechanical Engineering Research, 2011 (ICMER2011)

[13]. www.ivt.ntnu.no/.../LNG\%20Conferences/.../050202.pd.f, 2013

[14]. www.idmeb.org/.../LNG_Propulsion_02_29_38.pdf, 2013

[15]. Dundović Č., Basch D. and Dobrota Đ., (2009), Simulation Method for Evaluation of LNG Receiving Terminal Capacity, Promet - Traffic \& Transportation, 21(2), pp. 103- 112.

[16]. Faruque Hasan M. M, Zheng Minghan A. and Karimi I. A., (2009), Minimizing Boil-Off Losses in Liquefied Natural Gas Transportation, American Chemical Society, Industrial Engineering Chemistry Research, 48(21), pp. 9571-9580.

[17]. Sedlaczek R., (2008), Boil-Off in Large and Small Scale LNG Chains, Diploma Thesis, Faculty of Engineering Science and Technology, Department of Petroleum Engineering and Applied Geophysics, Trondheim, available at: http://www.ipt.ntnu.

no/ jsg/studenter/diplom/2008Sedlaczek.pdf, [accessed 12 December 2013].

[18]. British Petrol and International Gas Union, (2011), Guidebook to Gas Interchangeability and Gas Quality, available at: http://www.igu.org/igu-publications /Gas\% 20Interchangeability\% 202011\%20v6\%20HighRes.pdf, [accessed 17 January 2013].

[19]. McGuire, J. J. and White, B., (2000), Liquefied Gas Handling Principles on Ships and in Terminals, London: Witherby \& Co Ltd.

[20]. El-Gohary, M. Morsy. "The future of natural gas as a fuel in marine gas turbine for LNG carriers." Proceedings of the Institution of Mechanical Engineers, Part M: Journal of Engineering for the Maritime Environment 226.4 (2012): 371-377. 